\title{
ENFOQUE SOCIOLÓGICO PARA EL ESTUDIO DEL LIDERAZGO POLÍTICO
}

\author{
SOCIOLOGICAL APPROACH FOR THE STUDY OF POLITICAL \\ LEADERSHIP
}

\section{José Francisco Jiménez Díaz \\ Universidad Pablo de Olavide de Sevilla. España/Spain josefco@upo.es}

Recibido/Received: 29/04/08

Aceptado/Accepted: 14/07/08

\section{RESUMEN}

En este trabajo se desarrolla un enfoque sociológico para el estudio del liderazgo político. El enfoque sociológico del liderazgo está relacionado con su proceso de construcción social. Este proceso es analizado mediante los dos conceptos principales del "constructivismo estructuralista" de Bourdieu: habitus y campo del líder político. Conceptos que expresan las dimensiones subjetivas y objetivas del fenómeno del liderazgo y que se manifiestan en tres procesos interrelacionados: la socialización, la institucionalización y la legitimación de las prácticas políticas del líder.

\section{PALABRAS CLAVE}

Líder, habitus, campo político, construcción social.

\section{ABSTRACT}

This paper develops a sociological approach to the study of political leadership. The sociological approach of the leadership is related to the process of social construction. This process is analyzed by the two main concepts of Bourdieu's "constructivism structuralist": habitus and field of political leader. These concepts express the objective and subjective dimensions of the phenomenon of leadership. The subjective and objective dimensions are manifested in three interrelated processes: socialization, institutionalization and legitimization of the political practices of the leader.

\section{KEYWORDS}

Leader, habitus, political field, social construction.

\section{INTRODUCCIÓN}

El liderazgo ha sido una preocupación central en la teoría social y política clásica. Sin embargo, el liderazgo es uno de los fenómenos de la historia humana 
"más observados y menos entendidos" (Burns, 1978, citado en Rejai y Phillips, 1997:1). De hecho, después de varios milenios de historia y de los innumerables estudios sobre los líderes y/o dirigentes políticos que la han orientado, aún no disponemos de una concepción o definición del liderazgo universalmente aceptada. Además el liderazgo político se caracteriza por ser un campo de estudio especialmente incómodo, debido a su carácter multidimensional. Como ya señalaron Bass y Stogdill (1974) en su Handbook of Leadership, existen tantas definiciones de liderazgo como investigadores han intentado definirlo. Así, la Enciclopedia internacional de las ciencias sociales admitió que el liderazgo podía ser estudiado desde tres aspectos diferentes: psicológicos, sociológicos y políticos (Gibb, Tannenbaum y Seligman, 1979:589-608). Este trabajo se concentra en los aspectos "sociológicos" del liderazgo.

Gran parte de los sociólogos han visto en el liderazgo el ejercicio del poder o de influencia en colectividades sociales tales como grupos, organizaciones, comunidades o naciones. Ese ejercicio del poder está mediatizado por el carisma personal del líder, concepto escurridizo y de difícil delimitación, aunque "característica inherente al estudio del liderazgo político cuyo análisis no puede obviarse" (Deusdad Ayala 2001:212). En la práctica el poder de los líderes se ha aplicado a las tres funciones siguientes, muy generales y relacionadas entre sí: fijar los fines, metas u objetivos de la colectividad; crear las estructuras necesarias para alcanzar los fines de ésta; y mantener o reforzar esas estructuras. Los estudios sociológicos han dedicado especial atención a la última de estas funciones, en parte, porque es más susceptible de estudio empírico, especialmente en los contextos burocráticos que es donde se han realizado muchos de los estudios sobre liderazgo. El énfasis en la función de mantenimiento del orden social ha llevado a las teorías del liderazgo a su vertiente más "estática", por lo menos hasta los años setenta del siglo XX (Tannenbaum, 1979:597-598). El enfoque aquí propuesto para el estudio del liderazgo considera las tres funciones apuntadas anteriormente, haciendo énfasis en un proceso "dinámico" de construcción social del líder.

$\mathrm{Si}$ atendemos a las ideas que sobre el liderazgo político se han ofrecido a lo largo de la historia, se pueden distinguir tres enfoques principales (Rejai y Phillips, 1997:1-2). El primer enfoque coincide con los escritos de los grandes pensadores clásicos que se aproximan al estudio del liderazgo en términos del "Gran hombre" y sus rasgos distintivos. En este grupo están las siguientes caracterizaciones originales del líder: Platón y el Rey filósofo, Nicolás Maquiavelo y el Príncipe, Thomas Carlyle y el Héroe, Nietzsche y el Superhombre. A este grupo de estudios, en tanto que realzan las dimensiones subjetivas-personales del líder, se le llamará "visión subjetivista del liderazgo". Un segundo enfoque ha estado representado por grandes pensadores de la historia moderna y contemporánea, quienes acentúan el papel de las situaciones y contextos sociales en la formación de los líderes. En este grupo hallamos una múltiple relación de pensadores. Por ejemplo: Adam Smith y la mano invisible, Herbert Spencer y el Darwinismo social, Carlos Marx y la lucha 
de clases. A este conjunto de estudios, en tanto que destacan las condiciones objetivas-impersonales en las que se producen los líderes, los denominaremos "visión objetivista del liderazgo". Otro tercer grupo de investigadores intentan conciliar los dos enfoques anteriores, pues sólo en apariencia se presentan irreconciliables. Desde principios del siglo XX, una serie de estudiosos apuntan la necesidad de crear un ajuste entre el "hombre" y la "hora", parafraseando a William James. Un estudio que fusionó las dos escuelas tradicionales fue realizado por Stogdill (1974). Desde que se publicara el trabajo de Stogdill, todos los estudios sobre el liderazgo han reconocido la interacción de las características personales y de las situaciones sociales. De este modo, se ha desarrollado una teoría de la interacción, destacando la "dinámica" entre el líder, los seguidores, la situación y los objetivos implicados. Hollander (1978) desarrolló una teoría transaccional, la cual combina la aproximación situacional con un componente de intercambio social centrado en las influencias recíprocas entre el líder y los seguidores.

Uno de los más influyentes investigadores sobre liderazgo en las últimas décadas destaca varios aspectos de este fenómeno multidimensional y, por tanto, complejo. Burns (1978), en primer lugar, reconoce que el liderazgo es "disensión", ya que está basado en el conflicto y en el poder sobre la asignación autoritaria de valores para una sociedad. En segundo lugar, el liderazgo es "colectivo" ya que está envuelto en la interacción entre líder-seguidores. En tercer lugar, el liderazgo es "resuelto" y "determinado", en el sentido de que lleva a la creación de ideas, movimientos, instituciones, naciones. En cuarto lugar, el liderazgo adquiere dos formas diferentes dependiendo de los "objetivos" implicados. Por una parte, el liderazgo de transacción o negociación consiste en el intercambio entre líder y seguidores para aproximar necesidades recíprocas y deseos (intercambio de trabajos por votos); este tipo de liderazgo persigue valores como la sinceridad, honestidad y la responsabilidad. Por otra parte, el liderazgo transformador, además de intercambiar necesidades mutuas, elimina y sacrifica seguidores si llega el caso, ya que es moralmente elevado y persigue valores como la libertad, la igualdad y la justicia (Burns, 1978). Considerando críticamente esta perspectiva, Tucker (1981) ha equiparado la acción política con el liderazgo, instando a que cualquier aproximación al mismo debe ser neutral en términos de valores con objeto de que nos permita estudiar líderes tan inquietantes como Stalin y Hitler. Realzando la importancia que este enfoque y sus desarrollos recientes han otorgado a la combinación de las características personales del líder con los escenarios sociales en que realiza sus prácticas, lo denominaremos enfoque "integrador" del liderazgo. En este sentido, aquí proponemos un análisis integrador sobre el liderazgo político inspirado en la perspectiva del constructivismo estructuralista de Pierre Bourdieu. 


\section{ENFOQUE SOCIOLÓGICO DEL LIDERAZGO: CONSTRUCTIVISMO ESTRUCTURALISTA}

Como recientemente han reconocido diversos especialistas en el pensamiento de Pierre Bourdieu, casi nunca se le ha interpretado como a un sociólogo político. Sin embargo, su obra y buena parte de su actividad intelectual representan un "intento continuo y de enfoques múltiples por configurar una ciencia de las condiciones sociales que hacen posible la democracia -definida ésta en un sentido amplio como el estado social que permitiera a todo el mundo tener tanto la inclinación como la capacidad de acceder a los asuntos públicos- y detectar las dificultades y las posibilidades históricas de las luchas orientadas a propiciar su avance en los distintos ámbitos de nuestra vida" (Wacquant, 2005:23). Además, la sociología de Pierre Bourdieu es desde sus comienzos una sociología política en el sentido de que se ha desarrollado en estrecha relación con las grandes preguntas políticas que han sacudido a la sociedad francesa desde 1950: en primer lugar la Guerra de Argelia; después durante el gaullismo, la falsa democratización cultural; la crisis del sistema educativo como agente que contribuye a la reproducción social de la desigualdad; y posteriormente el cierre del mundo político seguido de los efectos de la política neoliberal de abandono del Estado (Champagne, 2005). De este modo, la producción intelectual de Bourdieu no ha pasado inadvertida en la sociedad francesa. Es más, su influencia ha sido más que notable en la sociología europea y norteamericana, como demuestran diversos intérpretes de su obra (Alonso, Martín Criado y Moreno Pestaña, 2004; Accardo y Corcuff, 1986; Corcuff, 1998; Gutiérrez, 2002; Wacquant 2005).

La tarea de la sociología, de acuerdo con Bourdieu, consiste en la comprensión científica, teórica y empírica, del sistema de poder y sus estrechas vinculaciones con las estructuras culturales (Oltra et al., 2004:513). Para llevar a cabo dicha tarea, Bourdieu desarrolla una perspectiva analítica denominada por él mismo como "constructivismo estructuralista" o "estructuralismo constructivista". Una perspectiva centrada en aprehender las diferentes prácticas sociales mediante la relación dialéctica entre las estructuras y los agentes, entre las relaciones objetivas (campo) y los fenómenos subjetivos o cognitivos (habitus). Cuando dice "estructuralista", el pensador francés, se refiere a "que existen en el mundo social mismo, y no solamente en los sistemas simbólicos, lenguaje, mito, etc., estructuras objetivas, independientes de la conciencia y de la voluntad de los agentes, que son capaces de orientar o de coaccionar sus prácticas o sus representaciones" (Bourdieu, 1988:128). Al decir "constructivismo", Bourdieu considera que "hay una génesis social de una parte de los esquemas de percepción, de pensamiento y de acción que son constitutivos de lo que llamó habitus, y por otra parte estructuras, y en particular de lo que llamó campo y grupos, especialmente de lo que se llama generalmente las clases sociales" (Bourdieu, 1988:128). Con esta perspectiva analítica el autor francés pretende disolver el dualismo convencional de 
la estructura y de la agencia que ha caracterizado la producción intelectual de las ciencias sociales desde sus orígenes hasta mediados del siglo XX. Para liberarse del determinismo estructural acude al enfoque fenomenológico y a la "intención", tratando de conciliar lo que la realidad social tiene de objetivo con lo que tiene de subjetivo (Castón Boyer, 1996:78). Cuando se habla de objetividad y de subjetividad se está hablando de una misma realidad, porque en el orden humano existen al unísono "interiorización de la exterioridad y exteriorización de la interioridad".

La dicotomía de las perspectivas objetivista y subjetivista presentes en los estudios clásicos sobre liderazgo político, ha constituido el obstáculo principal para la construcción de una teoría adecuada del liderazgo. Con el objetivo de resolver este problema, la teoría social de Bourdieu "tiene en cuenta la determinación de las estructuras objetivas y el proceso de construcción social que establecen los actores" (Ayerdi, 1994:275). Como reconoce Wacquant (2005:162), el toque distintivo de esta empresa es que "no se limita a los enunciados teóricos abstractos sobre el 'vínculo entre la cultura y el poder', sino que establece y lleva a cabo un programa detallado de investigación o, para ser más precisos, de "construcción de objetos". Aplicado a nuestro estudio, ello implica el análisis del "liderazgo político" en tanto que realidad "social" sometida a un "doble" proceso de construcción social (Berger y Luckmann, 1997). Por un lado, el líder político como "objeto social" que construyen los distintos investigadores, especialmente los politólogos, en participación conjunta y mediante diversas luchas sociales en las que están implicados dichos investigadores ${ }^{1}$. Por otro lado, el liderazgo, en tanto que realidad sometida a un proceso de construcción social, se caracteriza por ser relacional e interactivo, más que estrictamente "personal", sobre todo en lo referente a la relación del líder con sus seguidores reales y potenciales ${ }^{2}$, así como con otros agentes del campo político y del campo de poder en los que el líder intenta capitalizar sus intervenciones mediante las diferentes especies de capital en juego. Veamos.

\section{EL LIDERAZGO EN EL MARCO ANALÍTICO DEL HABITUS Y DEL CAMPO}

El marco analítico del constructivismo estructuralista aporta un conjunto de ideas y categorías de observación apropiadas para una mejor compresión del liderazgo político. Dicho marco contribuye a un estudio detallado de los líderes y su entorno social. En este sentido, consideramos muy relevante la elaboración de relatos de vida o relatos biográficos ${ }^{3}$ del líder político, como una técnica de investigación clave para indagar en el habitus del mismo, así como en las estructuras sociales en las que se encuentra inmerso y la configuración concreta del campo "político" que posibilita su acción como líder. A continuación exponemos de forma resumida los conceptos de habitus y campo, aplicados al estudio del 
liderazgo político. Como se ha referido, ambos conceptos son indispensables si pretendemos reconstruir una teoría y una investigación sobre liderazgo político basada en los planteamientos de Bourdieu.

El habitus del líder político consiste en las estructuras sociales de su subjetividad, la interiorización de las estructuras sociales y de las instituciones por el líder. El líder representa la historia de un grupo de personas o asociación, sea en sentido territorial (Estado, región o municipio), sea en sentido funcional (partido, sindicato u organización socio-política). Comprendido desde el habitus, el líder es parte de la historia de una institución o sociedad hecha cuerpo, interiorizada, a través de su voz, gestos, movimientos corporales, discursos, prácticas políticas, formas de sentir, formas de percibir la realidad y modos de valorar la misma. La persona que llega a ser líder es el encargado, en tanto que es reconocido por otros agentes sociales por una especie de "misterio", de representar las voluntades particulares.

El habitus se puede comprender de forma análoga al concepto de socialización primaria (infancia) y secundaria del líder (vida adulta). Asimismo, el habitus del líder está vinculado al fenómeno de la resocialización del líder; cambios profundos producidos en la socialización del líder, por ejemplo, entrada en una nueva institución, confesión religiosa, partido político, sindicato, institución educativa, universidad, etc. La socialización es un proceso constante e inacabado en la vida: empieza cuando nace el líder y sólo acaba al morir éste. Por ello insistimos en la importancia de recabar el relato de vida del líder como técnica de investigación necesaria para el análisis de su habitus ${ }^{5}$. Respecto a los procesos de socialización y resocialización del líder nos podemos preguntar: ¿terminan estos procesos al morir el líder? ¿Y el espectro simbólico que deja tras de sí el líder: lemas, emblemas, banderas, imágenes, edificios, leyes, costumbres, normas, creencias, etc.? Algunos líderes continúan socializando a sus potenciales seguidores incluso después de su muerte. He aquí el poder real y simbólico de los líderes: véase el caso de Lenin en la Unión Soviética (1924-1989). Un ejemplo más cercano para los españoles es el de Francisco Franco para una parte de los mismos después de 1975. Franco incorporó y representó el régimen "franquista", "por la gracia de Dios", hasta tal punto que su figura monopolizó el mundo sociopolítico de los españoles durante su mandato e incluso tras su muerte. Es significativo que muchos regímenes políticos, sobre todo los de cariz autoritario y totalitario, reciban el nombre propio de sus líderes incuestionables o dictadores. He aquí la huella "histórica" que deja el habitus del líder. En ese sentido, se podría decir que la "sombra" del líder (habitus) es alargada por sus seguidores.

Una definición general de habitus es la siguiente: "sistema de disposiciones perdurables y transferibles" (Corcuff, 1998:32). Analicemos esta definición, pues puede aportar luz para una comprensión más profunda del liderazgo político.

Disposiciones: inclinaciones a percibir, sentir, hacer y pensar de una determinada manera, interiorizadas e incorporadas -hechas cuerpo-, casi siempre de 
forma inconsciente, por cada individuo, dependiendo de las condiciones objetivas de su existencia y de su trayectoria biográfica y social. El líder y sus seguidores perciben, piensan y evalúan de una determinada forma la realidad socio-política, en función de sus condiciones sociales de existencia y de sus trayectorias personales.

Perdurables: aunque estas percepciones pueden modificarse durante las experiencias, están fuertemente enraizadas y tienden a resistir el cambio, marcando así una cierta continuidad en la vida personal del líder y sus seguidores. El líder y sus seguidores construyen una máscara tan sofisticada que intentan perpetuar de por vida. Muchas veces esa máscara está basada en elementos sobrenaturales ("por la gracia de dios" en el caso de Franco), que ayudan a prolongar el carisma del líder.

Transponibles: las disposiciones adquiridas merced a ciertas experiencias vitales (familiares por ejemplo) tienen efectos sobre otras esferas de la experiencia del líder (la carrera política profesional) y sus seguidores (formas de apoyar). Este es un elemento primordial en la unidad de acción y de visión del líder.

La idea de sistema como conjunto de elementos en interacción insiste en el aspecto relacional del liderazgo, tanto en sentido teórico para comprender el fenómeno social del liderazgo (perspectiva relacional), como en las prácticas reales del líder político que depende de las relaciones líder-seguidores, líder-instituciones, líder-opositores, etc. Por otro lado, la idea de sistema hace referencia a que las disposiciones tienden a estar unificadas. Según Bourdieu la unidad y la continuidad de la persona (líder), que suelen ser efecto del habitus, no son normalmente las que la persona se imagina consciente y retrospectivamente, sino resultado de la ilusión biográfica (Corcuff, 1998:33). Más bien la unidad y continuidad son en buena medida inconscientes, reconstruidas por el científico social, en función de la situación en el ámbito de las clases sociales, de las posiciones institucionales, de las sucesivas experiencias en diferentes campos y, por tanto, también de la trayectoria en el mundo social. Una reciente monografía sobre liderazgo que viene a confirmar estos argumentos es el excelente estudio biográfico del líder político de la transición española Francisco Fernández Ordóñez (Delgado Fernández y Sánchez Millas, 2007).

A tenor de los argumentos anteriores, las categorías de observación para estudiar el habitus de un líder político serían:

Primero.-La percepción y conocimiento que el líder adquiere de la realidad social (socialización, familia, proceso de escolarización y capacidades intelectuales),

Segundo.-Evaluación de la realidad que elabora el líder (lenguaje verbal: discursos políticos, diarios personales, ideología, creencias, valores, afiliaciones religiosas),

Tercero.-Los sentimientos que expresa el líder (lenguaje verbal: libros, diarios y notas personales, y lenguaje no verbal: voz, gestos), 
Cuarto.-Adopción de decisiones y fijación de la agenda (acción política en proyecto: prácticas políticas "presentes", agenda política del líder),

Quinto.-Las tareas políticas realizadas (carrera política realizada: prácticas políticas "pasadas", agendas políticas del líder),

Sexto.-Búsqueda de recursos y apoyos (redes de apoyo: redes sociales del líder en el espacio social, formas de apoyar al líder por sus seguidores).

Por otro lado, el campo político constituye el momento de expresión de la interioridad o subjetividad del líder y sus seguidores. En este momento el líder y sus seguidores manifiestan la historia -sus historias- en el campo político. El campo político es la historia del líder y sus seguidores convertida en cosas (instituciones), mediante el capital político, económico, cultural y simbólico que pone en juego el líder dentro de las instituciones que dirige (asociaciones, partido, Estado). El campo político es una esfera de la vida social que ha ido adquiriendo autonomía relativa a lo largo de la historia en torno a las relaciones sociales, intereses y recursos propios, diferentes de otros campos. El concepto de campo nos recuerda el modo en que Bourdieu concibe las instituciones no como sustancias, sino de manera relacional, esto es, como configuraciones de relaciones entre agentes individuales y colectivos. Los campos son espacios de juego históricamente constituidos con sus instituciones específicas y sus leyes de funcionamiento propias (Bourdieu citado en Gutiérrez, 2002:31). Las personas no se mueven por las mismas razones en el campo político, económico, artístico, universitario, periodístico, etc. Cada campo es al mismo tiempo un "campo de fuerzas"caracterizado por una distribución desigual de los recursos y por una correlación de fuerzas entre los dominantes y los dominados- y un "campo de luchas" -en el que los agentes sociales se enfrentan para conservar o para transformar esta correlación de fuerzas. En esas luchas puede estar en juego la propia definición del campo y su delimitación. Además, cada campo se caracteriza por relaciones de competencia entre sus agentes, por eso Bourdieu habla de "mercado". Sin embargo, la participación en el juego implica un mínimo de acuerdo sobre la existencia del campo.

Cada campo se caracteriza por mecanismos específicos de capitalización de sus recursos "legítimos". De acuerdo con Bourdieu, no hay una sola clase de capital tal como apreciara Marx (el capital económico), sino una multiplicidad de capitales (cultural, político, simbólico, etc.). Por lo que no existe una representación unidimensional del espacio social, sino una representación pluridimensional, estando compuesto el espacio social por diversos campos autónomos, cada uno de los cuales define modos de dominación específicos. De esta manera, no nos hallamos ante un "capitalismo", caracterizado por una forma determinante de dominación (la explotación económica), sino ante capitalizaciones y dominaciones diversas: relaciones asimétricas entre individuos y grupos, algunas de las cuales atraviesan diferentes campos (Corcuff, 1998: 34). Al mismo tiempo, 
estos modos de capitalización son autónomos, a veces compitiendo entre sí. Por ejemplo: el conflicto entre quienes detentan el capital cultural y los que poseen el capital político, intelectuales contra políticos, o viceversa. Otras veces los modos de capitalización se vinculan y se tornan acumulativos, aliándose los que detentan el capital económico y los que aspiran a obtener capital político. Por ejemplo, las alianzas entre los hombres de negocios y los políticos, orientando los primeros como han de actuar los segundos, o viceversa. Esto se puede ver claramente en la influencia y presión que ejercen los lobbies norteamericanos sobre la legislación y las políticas federales proyectadas por el Presidente de los Estados Unidos. O incluso más visiblemente el hombre de negocios que gana la presidencia de un gobierno (piénsese en Silvio Berlusconi, Italia) y acaba su mandato no sólo siendo más rico sino más poderoso, y mientras tanto otros agentes políticos han sido excluidos de la obtención de gran parte de los capitales legítimos en juego.

Lo que Bourdieu denomina "campo de poder" es un lugar donde entran en relación varios campos y capitales: es ahí donde se enfrentan, o se alían, los dominantes de diferentes campos. El campo de poder es un campo de luchas por el poder entre los que detentan distintos poderes. El concepto bourdesiano de campo de poder puede abrir nuevos horizontes en los estudios del liderazgo político, en la medida que el fenómeno del liderazgo político trasciende el propio campo político y enlaza con el campo cultural, campo económico, campo periodístico, etc. Es más, se puede apreciar como los líderes políticos del ámbito estatal acumulan gran capital cultural, en forma de títulos oficiales adquiridos en prestigiosas universidades públicas o centros educativos privados, poseen puestos públicos de trabajo como funcionarios en excedencia debido a que son titulares de una plaza obtenida en una oposición y, asimismo, acumulan el reconocimiento a las labores ejercidas durante su anterior carrera política como representantes locales, regionales o nacionales de su partido. Por esto, el campo político no es autónomo en el sentido que lo pueda ser el campo artístico o el campo intelectual respecto de otros campos. Más bien, el político es un campo que está vinculado a otros campos y capitales (cultural, administrativo, económico, periodístico), con los cuales establece una lógica de alianza o enfrentamiento y, de este modo, el líder político puede acumular o perder capitales de diversos campos y disfrutar de mayor o menor reconocimiento entre sus seguidores. De acuerdo con este razonamiento, el líder político gozaría de un gran volumen de capital "simbólico", en la medida que le sean reconocidos capitales acumulados anteriormente en distintos campos.

Considerando los anteriores argumentos las categorías de observación del campo político, vendrían dadas por las leyes generales de los campos sociales, las leyes específicas del campo "político" (véase ley 2) y el capital e intereses puestos en juego. De acuerdo con la interpretación de Gutiérrez (2002:31), las leyes generales de los campos sociales son leyes de funcionamiento invariable, válidas para campos tan diferentes como puedan serlo el campo económico, el político, el campo científico, el campo de la religión, etc. Dichas leyes generales son: 
En su aprensión sincrónica, los campos sociales se presentan como "sistemas de posiciones y de relaciones entre posiciones". Esto es, el líder poseerá poder en relación con otros agentes: seguidores, competidores, opositores.

Un campo social se define, entre otras cosas, definiendo "lo que está en juego y los intereses específicos del mismo". Cada campo engendra el interés que le es propio, que es la condición de su funcionamiento. En el caso del campo político lo que está en juego es el hecho de conseguir el poder político, el poder ejecutivo, la acción de gobierno local, regional o estatal. Dicha acción de gobierno, normalmente es dirigida por una persona (líder), junto con la ayuda de otras (asesores, concejales, consejeros, ministros), con el consentimiento de un grupo de seguidores (votantes, militantes, simpatizantes), la oposición y la pugna de un grupo de personas en desacuerdo explícito o implícito con la acción política del líder y su partido (opositores, competidores) $\mathrm{y}$, todo ello ubicado en un determinado escenario socio-histórico.

La estructura de un campo es un estado de la distribución, en un momento dado del tiempo, del "capital específico" que está allí en juego. Se trata de un capital que ha sido acumulado en el curso de las luchas anteriores y que orienta las estrategias de los agentes comprometidos en el campo.

La estructura de un campo es un estado de las "relaciones de fuerza" entre los agentes o las instituciones comprometidos en el juego. Así, la estructura de un campo puede identificarse como un "campo de fuerzas".

Un campo constituye un "espacio de luchas" destinadas a "conservar o a transformar dichas relaciones de fuerza". Es decir, es la propia estructura del campo, en cuanto sistema de diferencias, lo que está permanentemente en juego.

El campo social como campo de luchas no debe hacernos olvidar que los "agentes comprometidos" en las mismas tienen en "común" cierto número de "intereses fundamentales". El campo como complicidad básica acerca de lo que merece ser objeto de lucha, juego, apuestas y compromisos.

Al hablar de "luchas permanentes, de acumulación de capital, de estado de relaciones de fuerza", etc., estamos considerando a los campos en su aspecto "dinámico e histórico".

Asimismo, también se "definen y redefinen históricamente los límites de cada campo y sus relaciones con los demás campos". Ello conlleva una redefinición permanente de la autonomía "relativa" de cada uno de los campos. La autonomía del campo político es muy contingente, debido a que este campo está directamente relacionado con la definición del "campo del poder".

Efectivamente, en el campo del poder están en juego, mediante relaciones de fuerza y luchas sociales entre los diferentes agentes, la distribución relativa y la cantidad global del capital cultural, capital económico, capital político y el capital simbólico que puedan poseer dichos 
agentes. Es decir, las clases dominantes luchan por estos cuatro tipos de capitales y dependiendo de la cantidad de cada especie de capital y de su distribución relativa en el espacio social (volumen y estructura de capital), tendremos diferentes grupos de la clase dominante. El grupo de los intelectuales detentan gran volumen de capital cultural; poseen innumerables títulos escolares, conocimientos especializados en ciencias o artes concretas. El grupo de los dueños y directivos de grandes empresas ostentan gran volumen de capital económico (patrimonio y dinero) y capital social en forma de relaciones sociales. El grupo de los dirigentes de organizaciones políticas y los gobernantes ostentan gran volumen de capital político "institucionalizado", capital social en forma de relaciones sociales y capital cultural en forma de títulos escolares "superiores". Los nobles y aristócratas poseen gran volumen de capital social "institucionalizado" y capital cultural; detentan numerosos títulos de nobleza, nombramientos oficiales y títulos escolares. En la medida que cada grupo de la clase dominante posea capitales característicos de otros campos, ello incidirá en un mayor reconocimiento social por parte de quienes poseen más de una especie de capital (capital simbólico). El capital simbólico es el "capital económico o cultural cuando es conocido y reconocido" (Bourdieu, 1988:139). El capital simbólico es un capital de reconocimiento o de consagración. En definitiva, la distribución desigual del capital dentro de un campo lleva a posiciones diferentes. La posición es el lugar ocupado en cada campo, en relación con el capital específico que allí está en juego. Las posiciones son relativas y suponen pensarlas relacionalmente.

Sobre las ocho leyes antes comentadas, de modo especial la segunda ley que marca la especificidad del campo político, está cimentada la construcción social de todo líder político. Si profundizamos en el análisis de la segunda ley, observamos que el capital y los intereses "políticos" en juego, en un momento histórico determinado, van a estructurar el campo político en cuestión. Un capital político origina un campo específico con sus posiciones y relaciones entre posiciones, que llamaremos campo político. El capital político puede definirse como "conjunto de bienes acumulados que se producen, se distribuyen, se consumen, se invierten, se pierden" en un campo político (Costa 1976; citado en Gutiérrez, 2002:35). Concretamente, el capital político "proporciona a sus poseedores una forma de apropiación privada de bienes y de servicios públicos" (residencias, hospitales, escuelas, etc.)"6. La apropiación privada de bienes y servicios públicos implica la acumulación de poder material y poder simbólico para sus poseedores. El poder simbólico, junto con el poder político, implica la imposición de una visión de la realidad sobre los actores desprovistos de los recursos monopolizados por unos pocos (los líderes), en detrimento de los muchos (sus seguidores, opositores y competidores). Así, el líder se caracteriza por poseer una decisiva capacidad para la construcción y definición de la realidad sociopolítica con su lenguaje, sus palabras y sus clasificaciones. Así lo hizo Luís 
XIV cuando decía: "El Estado soy yo", célebre frase que rememora el inmenso poder ejercido por el "Rey Sol".

\section{CONCLUSIONES}

La perspectiva del liderazgo político como construcción social aquí desarrollada puede contribuir a la elaboración de un enfoque integrador del liderazgo. Un enfoque que integre las dimensiones subjetiva y objetiva del liderazgo se torna fundamental para la comprensión de la biografía, la historia y el aspecto relacional que implica el análisis del líder como realidad social. Pensamos que el enfoque teórico creado por Bourdieu, denominado "constructivismo estructuralista", está en disposición de aportar elementos analíticos apropiados para el análisis del liderazgo. En efecto, dichos elementos analíticos se derivan de las categorías de observación que posibilitan los conceptos de habitus y campo, aplicados al estudio del liderazgo político. Es muy importante que los estudios sobre liderazgo político no olviden "la perspectiva relacional y la dimensión histórica" que subyace en todo líder político.

En este sentido, el liderazgo político como construcción social implica diversas relaciones dialécticas: líder y sus seguidores; líder y su contexto; habitus del líder y su campo político; campo político y campo del poder. De este modo, pensamos que se torna esencial en la comprensión del liderazgo político el estudio de tres procesos interrelacionados. Estos tres procesos son: la socialización a que está sujeto el líder, esto es, el proceso de incorporación de la estructura social por la persona que un día representará las "voluntades" de un conjunto de agentes sociales (habitus). La institucionalización o proceso por el que el líder expresa su interioridad en el campo político y, que puede llevar a que la particular visión del líder sobre la realidad política influya en la estructuración del campo político. Por último, la legitimación de las prácticas políticas del líder, que implica a diversos agentes sociales (seguidores) reconociendo y aprobando la trayectoria, capitales y acciones políticas del líder, al tiempo que justificando esta situación de poder.

Considerando la interacción del líder como persona (habitus) y el líder como institución (campo), observamos la objetivación de la persona del líder en la historia. Ello nos lleva a la comprensión del líder político como 'agente histórico necesario pero no suficiente', pues se forma interactuando con otros agentes sociales en el origen, transformación y consolidación de las organizaciones políticas durante sus diferentes fases históricas. Organizaciones que pueden considerarse como grandes concentraciones de un tipo de capital o de diferentes tipos de capitales acumulados en las luchas sociales acontecidas dentro de los diversos campos. Efectivamente, los Estados-nacionales constituyen la acumulación de muy diversos tipos de capital, mientras que los partidos políticos implican la acumulación de un capital político jugado por sus líderes y seguidores a lo largo de su historia. Por tanto, un líder político estará legitimado para gobernar si 
le son reconocidos diversos capitales, pues el campo político no es autónomo. Estudiar el liderazgo político implica analizar los 'capitales' del líder.

\section{NOTAS}

${ }^{1}$ Considerar la construcción social de una realidad social, tal como lo es el liderazgo político, desde la perspectiva de Bourdieu, "implica plantear una manera de mirar y analizar los condicionamientos sociales que afectan al proceso de investigación, tomando como punto especial de la mirada, al propio investigador y sus relaciones" (Gutiérrez, 2002:1819). En concreto, las relaciones que mantiene el investigador con la realidad que analiza y con los agentes cuyas prácticas investiga (a), y, las relaciones que a la vez lo unen y lo enfrentan con sus pares y las instituciones comprometidas en el juego científico (b).

${ }^{2}$ Antonio Robles Egea afirma que la dimensión de construcción social del liderazgo político, en tanto tarea o invención colectiva, ha sido reconocida por gran parte de los estudios clásicos del fenómeno (Robles Egea, 2008). Asimismo, han reconocido dicha dimensión en sus investigaciones Natera Peral (2001) y Lucas (1999).

${ }^{3}$ Consideramos la definición de relatos biográficos que ha utilizado Daniel Bertaux en sus investigaciones. De este modo, "el relato de vida puede constituir un instrumento precioso de adquisición de conocimientos prácticos, con la condición de orientarlo hacia la descripción de experiencias vividas en primera persona y de contextos en los que esas experiencias se han desarrollado. Eso equivale a orientar los relatos de vida hacia la forma que un día propusimos llamar "relatos de prácticas" (Bertaux, 2005:21).

4 "Misterio" que no se llega a conocer en tanto no se comprende el particular habitus del líder político. Un elemento central de este "misterio" sería el particular carisma del líder político, el cual puede estar rodeado de elementos 'naturales, aprendidos y manufacturados' (Deusdad Ayala 2001:212). Es la cuestión del 'misterio del ministerio', como llamaban los canonistas (Bourdieu, 1988:142).

${ }^{5}$ Véase el trabajo de Boas Shamir y Galit Eilam (2005): "What's your story? A life-story approach to authentic leadership development", en The Leadership Quarterly, Volume 16, Issue 3, pp. 395-417. Asimismo es muy interesante el trabajo de Delgado Fernández y Sánchez Millas (2007).

${ }^{6}$ Bourdieu (1997:30). Asimismo, véase Bourdieu (2000).

\section{BIBLIOGRAFÍA}

ACCARDO, A. y CORCUFF, P. (1986): La Sociologie de Bourdieu, Burdeos, Le Mascaret.

ALONSO, L. E., MARTÍN CRIADO, E. y MORENO PESTAÑA, J. L. (2004): Pierre Bourdieu, las herramientas del sociólogo, Madrid, Fundamentos.

AYERDI, P. (1994): “Cultura y dominación en Pierre Bourdieu”, en Huarte de San Juan, Revista de la Facultad de Ciencias Humanas y Sociales (Universidad Pública de Navarra) 1: 272-292.

BASS, B. y STOGDILL, R. (1974): Handbook of Leadership, Nueva York, The Free Press. 
BERGER, P. L. y LUCKMANN, T. (1997): La construcción social de la realidad, Buenos Aires, Amorrortu.

BERTAUX, D. (2005): Los relatos de vida. Perspectiva etnosociológica, Barcelona, Bellaterra.

BOAS, S. y GALIT, E. (2005): "What's your story? A life-story approach to authentic leadership development", en The Leadership Quarterly 16, 3: 395-417.

BOURDIEU, P. (1988): "Espacio social y poder simbólico" en BOURDIEU, Cosas Dichas, Buenos Aires, Gedisa, pp. 127-143.

BOURDIEU, P. (1997): Razones prácticas. Sobre la teoría de la acción, Barcelona, Anagrama.

BOURDIEU, P. (2000): Intelectuales, política y poder, Buenos Aires, Eudeba.

BURNS, J. M. (1978): Leadership, Nueva York, Harper and Row.

CASTÓN BOYER, P. (1996): "La sociología de Pierre Bourdieu”, en Revista Española de Investigaciones Sociológicas, 76: 75-97.

CHAMPAGNE, P. (2005): "Hacer hablar a la gente. El uso social de las encuestas de opinión pública en democracia” en WACQUANT, L. El misterio del ministerio. Pierre Bourdieu y la política democrática, Barcelona, Gedisa.

CORCUFF, P. (1998): Las nuevas sociologías. Construcciones de la realidad social, Madrid, Alianza.

DELGADO FERNÁNDEZ, S. y SÁNCHEZ MILLAS, M. P. (2007): Francisco Fernández Ordóñez: un político para la España necesaria, 1930-1992, Madrid, Biblioteca Nueva.

DEUSDAD AYALA, M. B. (2001): El carisma político en la Teoría Sociológica, Barcelona, Universidad de Barcelona. Tesis Doctoral dirigida por Salvador Giner. Disponible en Internet: http://www.tdx.cesca.es/TDX-0913105-131822/ . [Consulta: 8 de abril de 2008].

GIBB, C. A., TANNENBAUM, A. S. y SELIGMAN, L. G. (1979): “Liderazgo", en David L. SILLS (dir.) Enciclopedia Internacional de las Ciencias Sociales, Madrid, Aguilar, vol. 6, pp. 589-608.

GUTIÉRREZ, A. B. (2002): Las prácticas sociales: una introducción a Pierre Bourdieu, Madrid, Tierradenadie Ediciones.

HOLLANDER, E. P. (1978): Leadership Dynamics, Nueva York, The Free Press.

LUCAS, F. de (1999): Líderes y liderazgos políticos, Madrid, Universidad Complutense, Tesis Doctoral Inédita dirigida por el Dr. Manuel Pastor Martínez.

NATERA PERAL, A. (2001): El liderazgo político en la sociedad democrática, Madrid, Centro de Estudios Políticos y Constitucionales.

OLTRA, B., et al. (2004): Sociedad, vida y teoría. La Teoría sociológica desde la perspectiva de Sociología narrativa, Madrid, CIS, pp. 511-517.

REJAI, M. y PHILLIPS, K. (1997): Leaders and Leadership. An Appraisal of Theory and Research, Westport, Preager Publishers.

ROBLES EGEA, A. (2008): "Elites, liderazgo y democracia. Liderazgo político y calidad de la democracia”, en VARGAS PAREDES, S. (ed.) Liderazgo esencial. Ejemplos de América Latina, México, Porrúa.

STOGDILL, R. M. (1974): “Leadership Traits: 1904-1947”, en Handbook of Leadership, Nueva York, The Free Press.

TANNENBAUM, A. S. (1979): "Liderazgo: aspectos sociológicos", en David L. SILLS (dir.) Enciclopedia Internacional de las Ciencias Sociales, Madrid, Aguilar, vol. 6, pp. 597602. 
TUCKER, R. C. (1981): Politics as Leadership, Columbia, University of Missouri Press. WACQUANT, L. (coord.) (2005): El misterio del ministerio. Pierre Bourdieu y la política democrática, Barcelona, Gedisa.

\section{Breve currículo:}

\section{José Francisco Jiménez Díaz}

Profesor Colaborador Doctor del Departamento de Derecho Público en la Universidad Pablo de Olavide de Sevilla. Licenciado en Ciencias Políticas y Sociología por la Universidad de Granada en 1998. Doctor en Sociología por la Universidad de Granada (2004). Principales líneas de investigación: Historia de las teorías políticas, liderazgo político y procesos de globalización. Entre sus publicaciones más recientes cabe destacar: Introducción a la historia de las ideas políticas contemporáneas. Desde la Revolución Francesa a la Revolución Rusa, (2008). "Un proceso de glocalización en su contexto sociopolítico: migraciones hacia el poniente almeriense", (2008). 